\title{
Drilling and bolting rigs operator support using FGS (Feeder Guiding System) and remote control
}

\author{
Łukasz Sarecki, Lesław Ostapow, \\ Piotr Ławicki, Paweł Mendyka \\ Mine Master Ltd., Poland
}

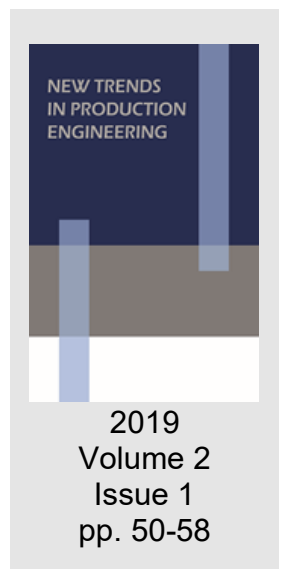

Date of submission to the Editor: 05/2019

Date of acceptance by the Editor: 07/2019

\section{INTRODUCTION}

Drilling and bolting rigs are the primary machines used in modern hard rock mining. Due to the necessity of excavating mineral resources from ores lying in more and more difficult geological conditions, such as mining areas and excavations even below 1000 meters. Other tough conditions observed in these mining areas are characterized by large longitudinal and lateral inclinations as well as low excavation height (in range of $1.6 \mathrm{~m} \div 2.5 \mathrm{~m}$ ). There is also a very strong retraction of the mining floors and high ambient temperature, even over $45^{\circ} \mathrm{C}$. Additionally, such excavations are exposed to rock bursts, and uncontrolled rock falls. Because of all these conditions, it is necessary to introduce specialized, modern mining machinery in such areas (Derlukiewicz, D., Karliński, J., 2012).

To help machine operators effectively work under those very hard mining conditions, global machine manufacturers use various types of mechatronic operator assistance systems, such as the drilling support system - in the version used by Mine Master company such system is called FGS (as an abbreviation Feeder Guiding System), bolting support system or remote control systems. The proper functioning of the machine is also monitored by the monitoring system of its most crucial parameters.

All these systems improve the comfort and safety of miners, and the remote control system also allows the operator of the machine to be moved away from the danger zone to a zone with a higher level of safety or friendlier working conditions (such as zones with better ventilation or lower air temperature). In Poland, such systems are used primarily in copper ore mines, which are now beginning to exploit deposits lying at greater depths, in very unfavorable mining and geological conditions (Kotwica, K. 2008). 


\section{DRILLING SUPPORT SYSTEM}

The first described operator support system is the one designated to simplify drilling process. To achieve that, drilling rig has been equipped with various onboard systems, which combine to create an advanced assembly for controlling the working unit. Together with the operator interface, such assembly creates a complex drilling support system. An important part of this system is the so-called FGS (Feeder Guiding System), which facilitates the positioning of the working unit in the correct position and orientation, according to the approved drilling pattern.

The main task of the drilling support system is to automatically drill the blast hole to the desired length. If the machine is also equipped with the FGS system, the length of the hole to the algorithm is taken from this system. However, depending on the conditions, the length of the hole in the FGS system can be taken from the blasting pattern, or if the operator decides so, he can choose the option of manually entering the length of the hole. Using the designated switch, the operator enters the automatic boring mode, and then the drilling process is started via the start button. At any time, it is possible to stop a given process through the pause button(Ostapów, L., Ławicki, P. 2016). On Figure 1 the operator screen mounted on the drilling rig is shown.

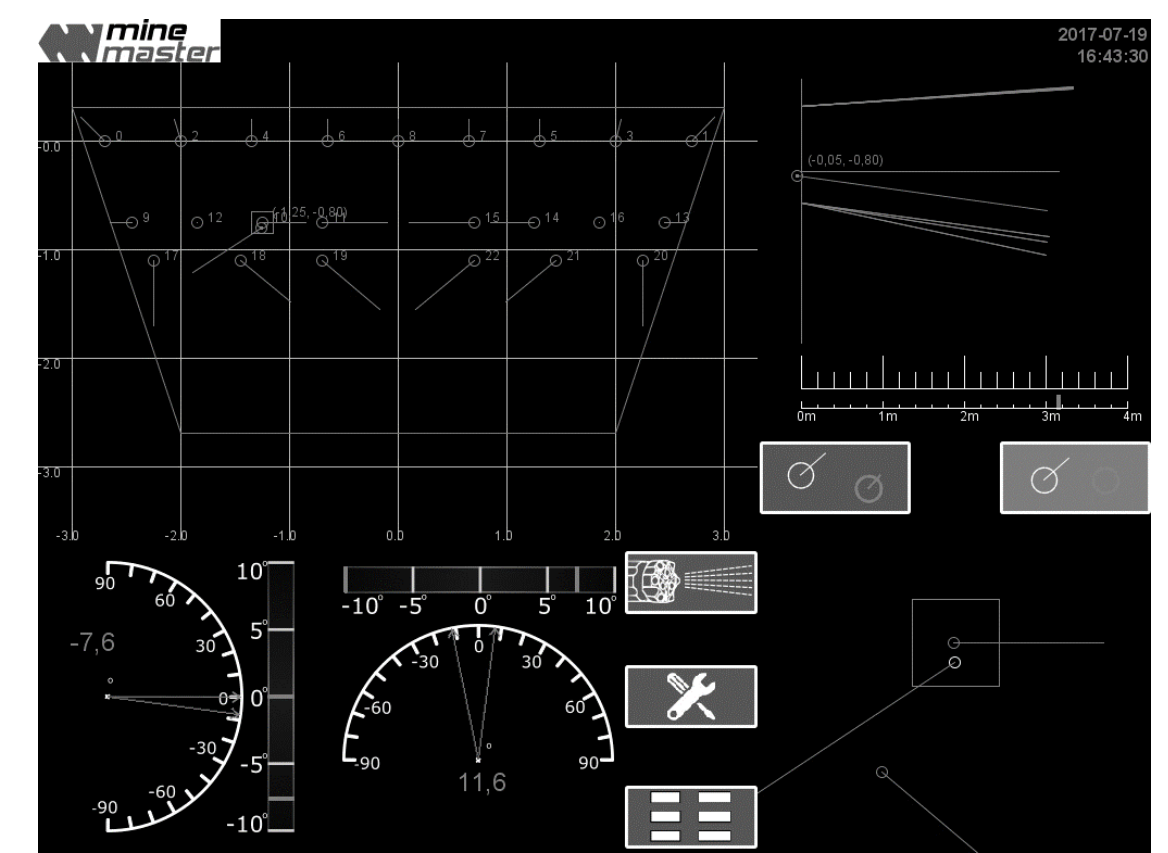

Fig. 1 Feeder Guiding System main panel view, intended to facilitate positioning of drilling working unit

Other operator mechatronic support systems installed on modern mining rigs (such as used by Mine Master Company) includes automatic mounting of the bolt roof support or the system for monitoring the work parameters of the entire rig. An analogous system for the presented drilling rig operator support is also used in case of bolting machines. Bolting process by the machine point of view can be separated into two main stages: drilling the hole for the bolt and bolt installation. 
When bolting support system is active, the process of drilling holes for bolts is carried out automatically. The operator screen shows all the information needed to observe and diagnose and diagnose the correctness of this process. In case of emergency situations, the operator is able to interrupt the drilling, finish it manually or fix the fault so that it will be possible to complete the drilling in automatic mode. The entire process is registered with a fixed time interval, set as required. Registration and monitoring of the drilling parameters can be later used to determine whether the operator during the drilling process does not change the settings or pressures that can affect the fault-free operation of the working unit. Saved data will also help in creating improvements or modifications on the next machines. After correctly drilling the hole, the glue is inserted either manually or using special glue applicator. In the meantime, the turret automatically prepares the bolt and sets itself in the bolt installation position. The system is waiting for confirmation by the operator of the start of the automatic second stage of roof anchoring process (Minemaster.eu, 2019).

Similar as with drilling, the bolt installation process is completely automatic. It is important to ensure the highest possible efficiency of this process due to the relatively fast glue bonding time. Since this bonding time is determined as the limiting factor, the entire process must be carried out during this period. Similarly to drilling, the entire anchoring process is registered and showed on the operator panel. Due to the costs associated with the incorrectly installed anchor and the danger it causes, it is apparent how important it is to ensure the highest possible accuracy and efficiency. Therefore, the data set of bolt installation process is regularly thoroughly analyzed. Also, using this data combined with the data collected during the drilling process, the impact of the precision of drilling a bolt hole on the later bolt successful installation can be seen. On Figure 2 the view of the operator's control panel during bolt installation is shown.

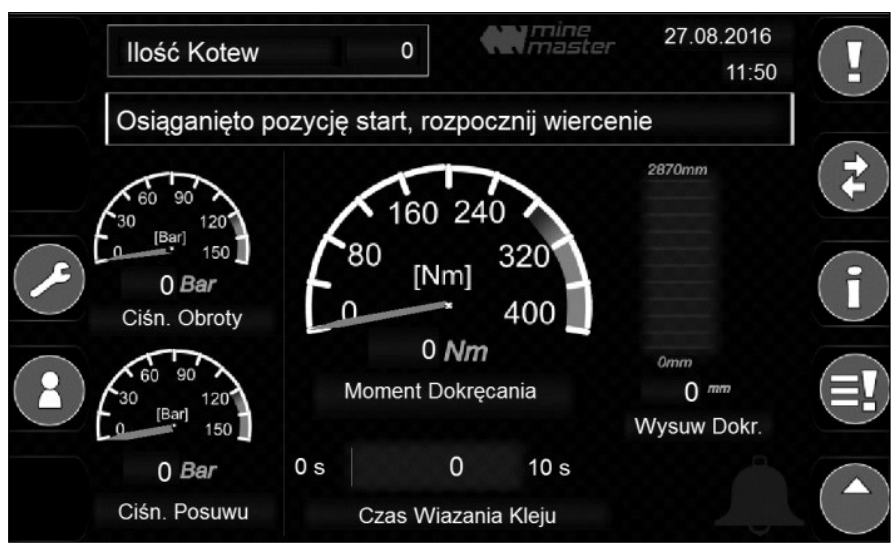

Fig. 2 Bolting installation support system - view of the operator control panel

\section{REMOTE CONTROL SYSTEM}

Keeping in mind the safety of operators of self-propelled machinery, as well as natural and technical threats occurring in underground metal ore mines, it is possible to assume that usage of rigs equipped with remote control systems can be successfully applied. Such zones incudes chambers with a higher 
concentration of hydrogen sulfide or other poisonous gases or areas with identified high rock burst or excavation collapse risks. Other areas where the remotely controlled operation is desirable are zones where blasting operations were conducted earlier, and there is a risk of encountering old, not blasted explosive charges - unexploded ordinances. Although the first machines operating in such areas in most cases are loaders and haulers, the highest risk of firing up unexploded ordnance arises during drilling. Special drilling rigs, additionally armored and equipped with remote control systems can successfully operate in such conditions without the risk of injury or death of the operator (Mendyka et al. 2017).

In the case of using remote control systems in the conditions of the underground mines, three previously possible solutions should be considered: a system with transmission of radio control signals, a system using data transmission lines through a fiber optic cable, stretched along the power cord or directly using the control wires integrated within the power cord supplying the machine (Paul, R.P. 1981).

Each of these solutions has its advantages and disadvantages. The system using radio waves does not require an extension between the machine and the cable operator, which facilitates the operator's work and does not pose a risk of damaging such a conductor. However, the operating range of such a system can be limited to only a few dozen meters - as authors tests have proven, in most cases maximal operation range does not exceed $60 \mathrm{~m}$. In addition, the use of such control in the case of a pillar-chamber ore exploitation system may require the use of additional elements (signal propagators) allowing the signal to passthrough the set of right angles on with excavation is shaped. Exemplary remote control system produced by Cavotec Company, suitable to work in underground mining conditions, is shown in Figure 3.

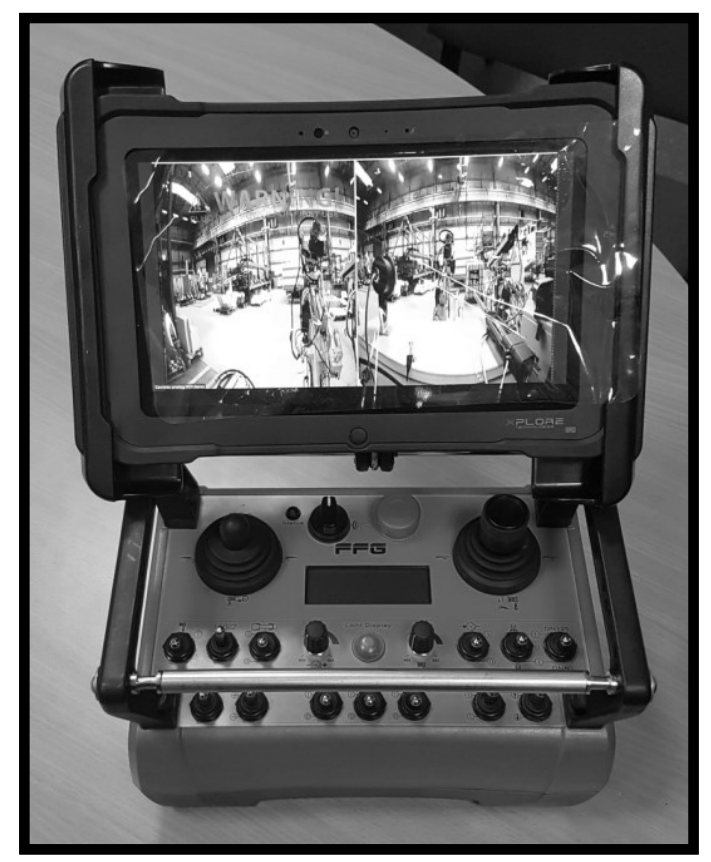

Fig. 3 Drilling rig remote control produced by Cavotec company 
In the case of control using a fiber optic cable or power cord, the range of machine control is virtually unlimited, but in practice operation range rarely exceeds 100-150 meters (distances traveled by drilling and bolting rigs in operating fields when moving between the chambers being drilled). The power cord that supplies the machine during drilling or bolting is usually wound on a drum mounted on the rig chassis, and the total length of the cord does not exceed more than 80 meters. From this point of view, it can be assumed that the distance between the place of remote control and the machine will not be greater than 80 meters (Mendyka et al. 2016).

The power cord may have included within it structure so-called control wires, which can be used to transmit signals, but in state-of-the-art solutions the signal transmitted by this type of cables is slightly disturbed. However, the advantage of such a cable is its high tensile strength.

Optical fiber has much better parameters for transmitting control signals, but the most significant factors of their application are maintaining proper cleanliness of plugs. It is, therefore, necessary to provide additional protection against contamination of the cable connector.

The remote control system, in addition to the remote commands transmitted from the operator to the rig, should also allow transmission in the opposite direction - that is from the machine to the operator. Transmitted in this way must be both information about the current state of the machine, as well as a video signal showing its current behavior. Without the image transmission, the functionality of the remote control system is limited to working in conditions in which the operator is able to control the behavior of the working system with his own eyes.

Simulation tests have shown that for sufficiently good visualization of the machine's operation, it is necessary to install at least two cameras, located stereoscopically. Taking additionally into account the habits of machine operators, as well as the ergonomics of using the system, it is advisable to mount a redundant, third camera located centrally, which overlaps the visualization area with the previous two, as well as a zone of limited or even zero visibility of the working system, but it is a natural image for the machine operator, usually working from the cabin position. Figure 4 shows simulations of the stereoscopic view of the rig in underground conditions. On Figure 5 illustration of the real control system, equipped with two cameras, is also presented.

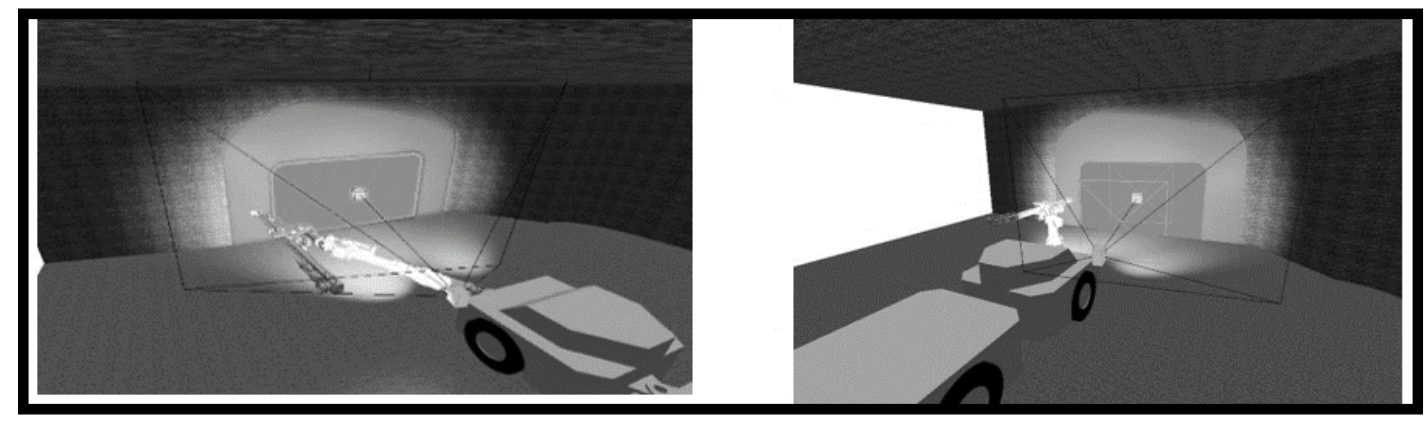

Fig. 4 Computer simulation of remote drilling rig control using stereoscopic cameras 


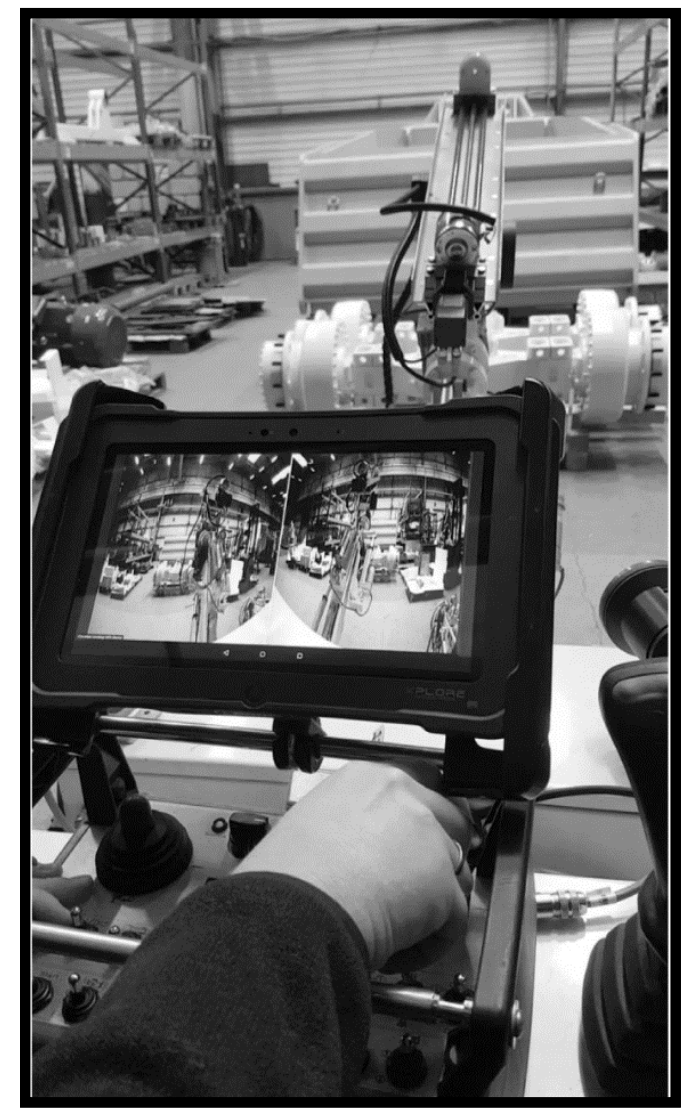

Fig. 5 Actual view of remote control system of the drilling rig

\section{MONITORING AND DIAGNOSTIC OF UNDERGROUND RIG}

The modern underground mining rigs has been equipped with several systems responsible for collecting data about the work parameters (Kwasniewski et al. 2013). The main onboard system is responsible for the machine's operation while moving. As a result, the driving parameters are monitored in the form of speed and distance traveled, the current position of the acceleration and brake pedals and its change over time. In order to ensure the correct range of the machine parameters during driving, suitable calculations are provided to the operator such as the possible distance to travel on the current electric battery load or gas tank fill, taking into account the last average energy consumption. Other monitoring system includes constant background of the machine's power supply system connected to the stationary installation in the mine. On the basis of data from this system, the operator receives information about the parameters of the mining network and how these parameters will affect the battery charging. Apart from those, the working unit is also fully measured and monitored during operation. Such system collects information about the current working state of the rig and the efficiency of the operator. Also, in automatic mode, the monitoring assembly is a part of a larger system that controls the hydraulics according to algorithms in order to drill the desired hole or install the bolt support. On Figures 6 and 7 the main monitoring systems of typical underground mining rigs are shown (both rigs originates from Mine Master company, Minemaster.eu, 2019). 


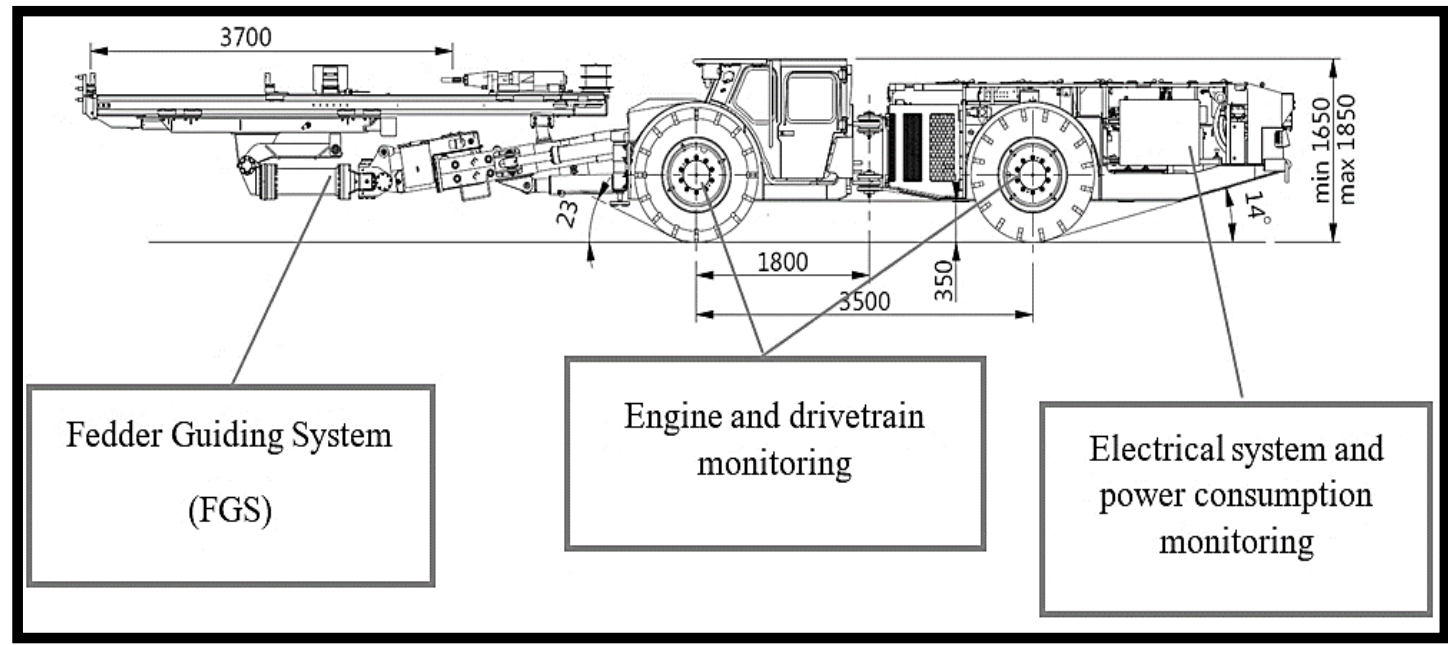

Fig. 6 Monitoring systems installed on a typical drilling rig Source: (Mine Master Face Master 1.7L presented)

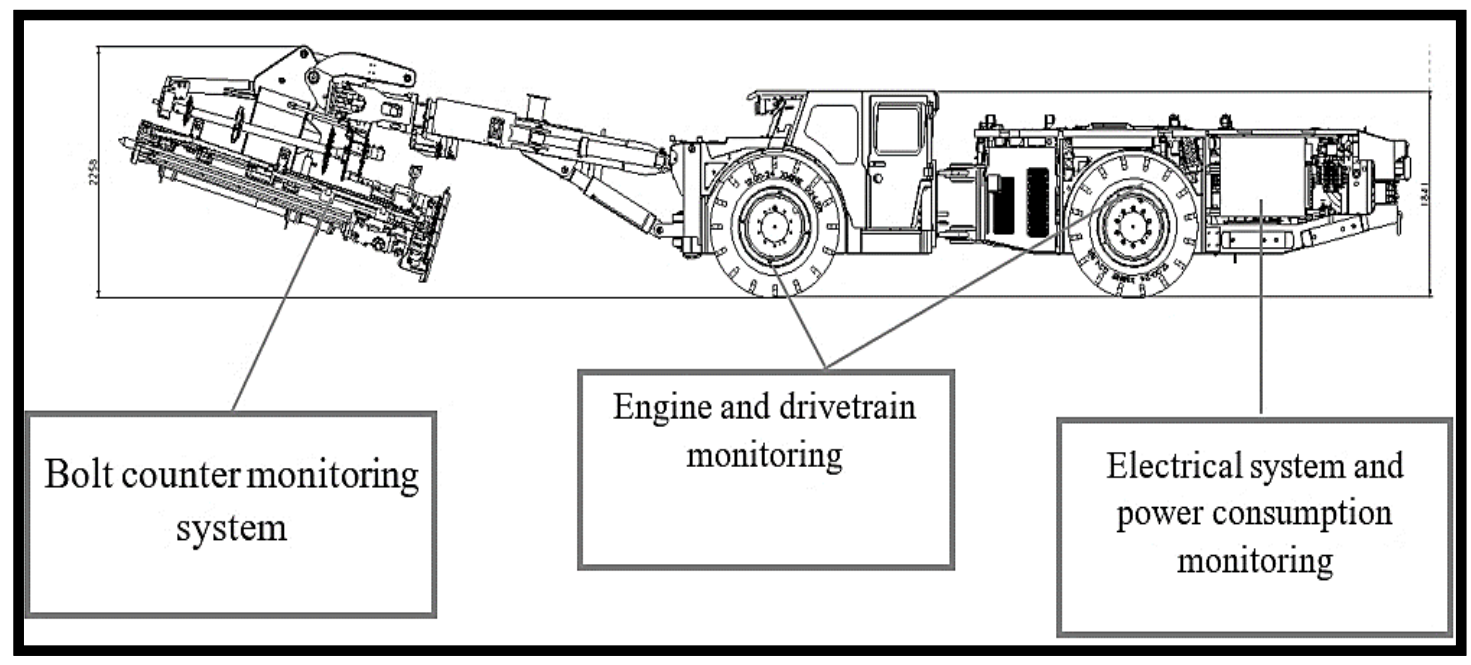

Fig. 7 Monitoring systems installed on the typical bolting rig Source: (Mine Master Roof Master 1.7 presented)

The monitoring systems collect data from the various components of the rig. Collected data after appropriate processing are sent to the recorder and saved in the desired format of files. Those data are synchronized with machine user servers at regular intervals.

Below, on Figure 8, the automatic report generation option using such data is presented. In addition to a predetermined report format (defined by machine owner), parameter analysis can include any configured graphs with parameters, both measured directly and calculated. For a more accurate analysis, it is also possible to change the time interval on the X-axis, which for example allows analyzing each drilled hole separately. 


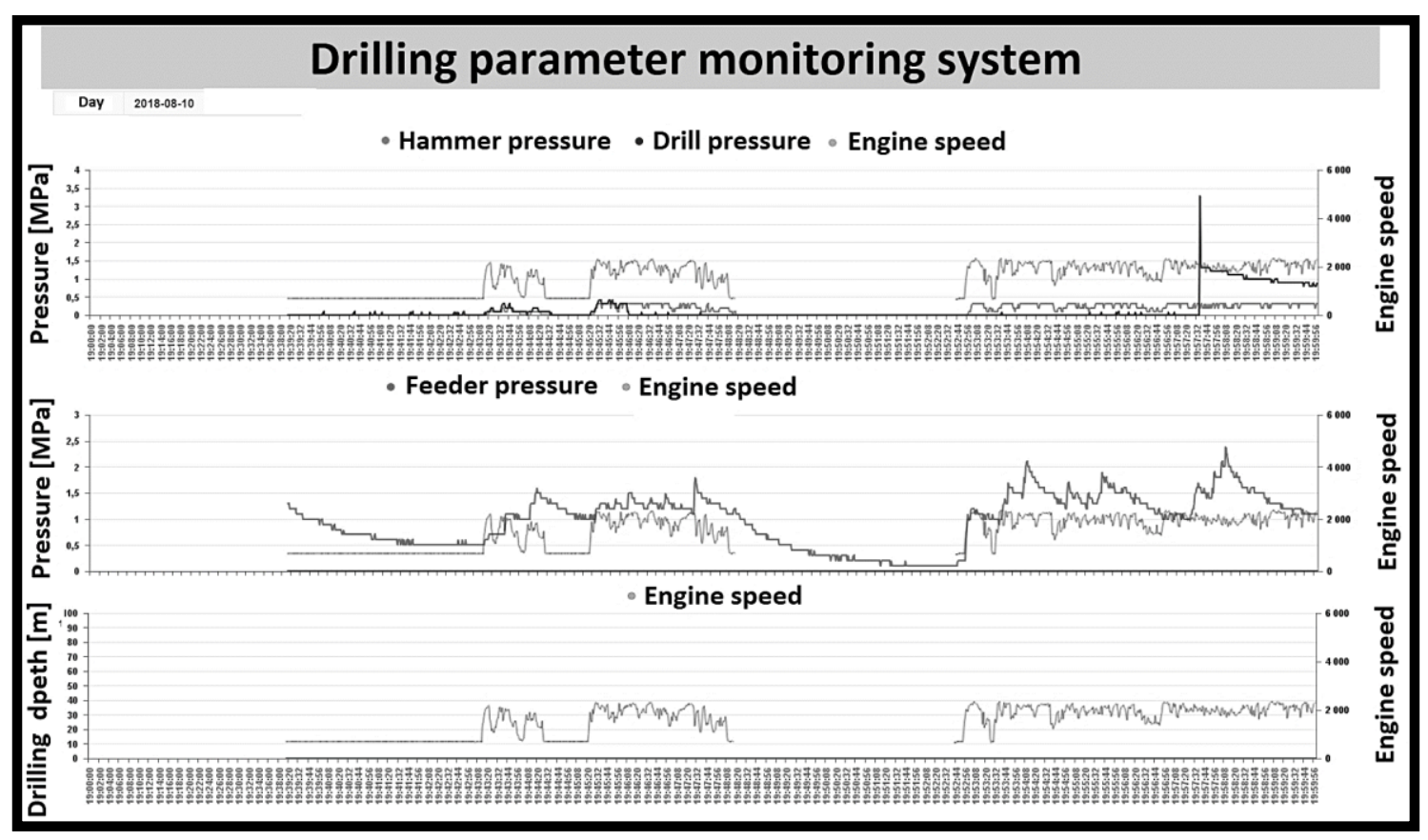

Fig. 8 Exemplary graphs of measured working parameters of the underground mining rig

\section{CONCLUSION}

As is known from industrial practice, in the case of underground mines, the natural hazards are able, even with the best technical equipment, to cause significant losses in the mine infrastructure and, more importantly, cause a threat to health and life of mine employees. In addition, these hazards cannot be fully monitored to obtain information on where and when a dangerous situation will occur - therefore, the best solution is to lead people from areas at risk.

In the case of coal mines, there are already automatic control and monitoring systems for longwall complexes. They limit the presence of service during the operation of such a complex to the necessary minimum, increasing its safety and comfort of work, and also in many cases increasing the efficiency of such automatically controlled complexes. In the case of metal ore mines, this type of work is still under development and it seems a matter of time to replace mobile machinery operators working especially at extraction departments exposed to an increased level of threats by remote systems used to control and monitor the condition of machinery, while their operators will ultimately operate control systems from a safe zone, staying for example in air-conditioned rooms (Karliński et al. 2016).

Nowadays, when still operators presence in underground zones are often necessary, a lot of electronic support systems are used to simplify operators work and improve their efficiency. The choice of a specific support system solution - for example in remote control case the one with radio wave control, fiber optic cable or power supply cable should be preceded by both analytical tests and in-situ verification, preferably in the underground mine. As a result of these tests, the future user should get an answer about the required scope of the proper functioning of a given system and reliability of its operation in underground conditions. 


\title{
ACKNOWLEDGMENTS
}

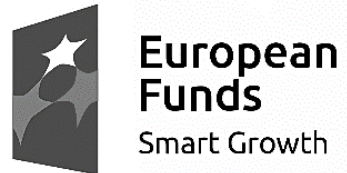

\author{
European Union \\ European Regional \\ Development Fund
}

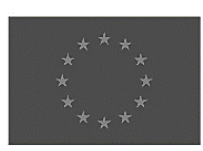

The project has been co-financed by the European Regional Development Fund under the agreement no. POIR.01.01.01-00-D011/16.

\section{REFERENCES}

Derlukiewicz, D., Karliński, J. (2012). Static and dynamic analysis of telescopic boom of self-propelled tunnelling machine. Journal of Theoretical and Applied Mechanics, 50, 47-59.

Karliński, J., Ptak, M., Działak, P., Rusiński, E. (2016). The approach to mining safety improvement: Accident analysis of an underground machine operator. Archives of Civil and Mechanical Engineering, 16(3), 503-512.

Kotwica, K. (2008). Scenarios of technological development of roadways mining in polish coal mines conditions. Gospodarka Surowcami Mineralnymi $=$ Mineral Resources Management, 24(1), 139-152.

Kwasniewski, J., Kravtsov, Y., Dominik, I., Dorobczynski, L., Lalik, K. (2013). SelfExcited Acoustical System for Stress Measurement in Mass Rocks. Journal of Low-Frequency Noise, Vibration and Active Control, 32(1-2), 133-144.

Mendyka, P., Kotwica, K., Stopka, G., Gospodarczyk, P., Bołoz, Ł. (2016). The design and analysis of drilling and bolting rigs for narrow vein exploitation. International Multidisciplinary Scientific GeoConference: SGEM: Surveying Geology \& Mining Ecology Management, 2, 881-888.

Mendyka, P., Kotwica, K., Stopka, G., Gospodarczyk, P. (2017). Dynamic and durability tests of drilling rig for narrow vein deposits. International Multidisciplinary Scientific GeoConference: SGEM: Surveying Geology \& Mining Ecology Management, 17(1.3), 275-282.

Minemaster.eu, (2019). Mine Master Company Official Website. [online] Available at: http://www.minemaster.eu/ [Accessed 20 May 2019].

Ostapów, L., Ławicki, P. (2016). Mechatroniczny układ sterowania dla ciągłej kontroli procesu wiercenia. Transport Przemysłowy i Maszyny Robocze, (4), 29-31.

Paul, R. P. (1981). Robot manipulators: mathematics, programming, and control: the computer control of robot manipulators. Richard Paul.

\begin{abstract}
.
The article presents the assumptions and main functionalities of two operator support systems - the FGS (Feeder Guiding System) and the remote control system of a drilling or bolting rig. Both of these systems greatly facilitate the work of an operator of a self-propelled mining vehicle in the conditions of an underground metal ore mine. The first of the described system allows for real-time control of the current position of the mining boom and facilitates the drilling of blast holes according to a predetermined drilling pattern. The second of the systems - a remote control system - is used especially in conditions of unstable rock mass or in the case of work in particularly difficult operating conditions, where it is advisable to limit the presence of the crew from the face-up to the necessary minimum. The intensity of these vibrations was related to the conditions of the cutting process.
\end{abstract}

Keywords: drilling rig, bolting rig, drilling control, remote control, drilling feeder system 